\title{
NILAI-NILAI RELIGIUS ISLAM \\ DALAM ANTOLOGI CERPEN "CARAKU MENCINTAI KANG ALFI (ALFIYAH LATIN)" KARYA LIA HIMMATUL ULYA
}

\author{
Moh. Syamsul Ma'arif ${ }^{1}$, Asngadi Rofiq ${ }^{2}$ \\ e-mail: asngadirofiq@iaida.ac.id ${ }^{1}$, syamsulmaarif@iaida.ac.id ${ }^{2}$ \\ Prodi Tadris Bahasa Indonesia \\ IAI Darussalam Blokagung Banyuwangi
}

\begin{abstract}
Abstrak
Karya sastra terutama cerpen merupakan salah satu sarana pengajaran untuk mengembangkan jiwa, memanusiakan manusia, dan menambah apresiasi sastra secara mendalam serta mencintai, mewarnai cerpen sebagai salah satu bentuk dari manifestasi kehidupan. Sebagai salah satu bentuk karya sastra, dalam cerpen juga diceritakan berbagai kehidupan manusia dan interaksinya dengan lingkungan dan sesamanya. Salah satu karya sastra dalam bentuk cerpen yang sangat membangun jiwa dan karakter anak bangsa Indonesia salah satunya adalah cerpen yang berjudul "CARAKU MENCINTAI KANG ALFI (ALFIYAH LATIN)" Karya Lia Himmatul Ulya. Genre cerpen ini sangat berbeda dengan cerpen-cerpen yang lain. Penulis sangat pandai menyuguhkan isi cerpen ini sehingga apik dan menyentuh saat dibaca. Cerpen ini juga menyajikan nilai-nilai religius yang berhubungan dengan Allah dan antara manusia itu sendiri. Antologi cerpen ini disamping memberikan hiburan juga menanamkan nilai-nilai religius dengan bahasa yang familier sehingga dapat mudah dipahami dan diimplementasikan oleh para pembaca dalam kehidupan sehari-hari.

Tujuan umum penelitian ini adalah untuk mengkaji nilai-nilai religius Islam dalam cerpen CARAKU MENCINTAI KANG ALFI (ALFIYAH LATIN) Karya Lia Himmatul Ulya yang bersumber dari Al-Qu'ran dan Al- Hadits. Tujuan khusus dari penelitian ini adalah (1) memperoleh deskripsi objektif tentang nilai- nilai religius dalam hubungan dengan Allah (vertical) dan (2) memperoleh deskripsi objektif tentang nilai-nilai religius dalam hubunganya dengan sesama manusia (horizontal). Penelitian ini menggunakan pendekatan kualitatif, dengan ciri-ciri (1) menggunakan latar alamiah sebagai sumber data langsung dan sebagai instrumen utama, (2) bersifat deskriptif, (3) lebih memperhatikan proses dari pada hasil, (4) menganalisis data secara induktif dan makna. Penelitian ini tergolong kedalam penelitian kualitatif deskriptif. Data dalam penelitian ini adalah nilai-nilai religius teks cerpen CARAKU MENCINTAI KANG ALFI (ALFIYAH LATIN), Sumber penelitian ini adalah cerpen yang berjudul "CARAKU MENCINTAI KANG ALFI (ALFIYAH LATIN)" Karya Lia Himmatul Ulya.

Berdasarkan hasil penelitian yang bersifat deskriptif tersebut ditemukan bahwa nilai-nilai religius Islam yang terdapat dalam cerpen CARAKU MENCINTAI KANG ALFI (ALFIYAH LATIN) ini meliputi "Hablum minallah dan Hablum minan-nas". Dalam hubungannya dengan Allah ditemukan tujuh nilai- nilai religius, yakni: (1) nilai keimanan (2) nilai ikhtiar, (3) nilai tawakkal, (4) nilai kesabaran, (5) nilai hidayah, (6) nilai tauhid, (7) pertolongan Allah, sedangkan dalam hubungannya dengan sesama manusia ditemukan tiga nilai religius, yakni: (1) saling tolong menolong antar sesama umat manusia, (2) saling menghormati dan menghargai sesama manusia, (3) toleransi antar umat beragama. Dari beberapa nilai religius yang disuguhkan penulis dalam cerpen ini menyuarakan konsep Aqidah Islam yang dapat
\end{abstract}


dijadikan tauladan yang baik bagi para pembaca. Karena isi cerpen ini banyak mencakup ajaran agama yang bersumber dari Al-Qur'an dan Al-Hadits. Dan dari sini pula penulis memberi penekanan betapa pentingnya hubungan manusia dengan Allah dan hubungan manusia dengan sesama manusia.

kata kunci: nilai-nilai, religius, dan cerpen.

\begin{abstract}
Literary works, especially short stories, are one of the teaching tools to develop the soul, humanize humans, and increase literary appreciation in depth and love, coloring short stories as a form of manifestation of life. As a form of literary work, the short story also tells about various human lives and their interactions with the environment and each other. One of the literary works in the form of short stories that really builds the soul and character of Indonesian children, one of which is a short story entitled "CARAKU MENCINTAI KANG ALFI (ALFIYAH LATIN)" by Lia Himmatul Ulya. This short story genre is very different from other short stories. The author is very good at presenting the contents of this short story so that it is neat and touching when read. This short story also presents religious values related to God and between humans themselves. This anthology of short stories in addition to providing entertainment also instills religious values with familiar language so that it can be easily understood and implemented by readers in everyday life.

The general purpose of this study is to examine Islamic religious values in the short story CARAKU MENCINTAI KANG ALFI (ALFIYAH LATIN) by Lia Himmatul Ulya, which is sourced from the Qur'an and Al-Hadith. The specific objectives of this study are (1) to obtain an objective description of religious values in relation to God (vertical) and (2) to obtain an objective description of religious values in relation to fellow human beings (horizontally). This study uses a qualitative approach, with the characteristics of (1) using a natural setting as a direct data source and as the main instrument, (2) descriptive, (3) paying more attention to the process than the result, (4) analyzing the data inductively and meaning. . This research is classified into descriptive qualitative research. The data in this study are the religious values of the short story text CARAKU MENCINTAI KANG ALFI (ALFIYAH LATIN).

Based on the results of this descriptive research, it was found that the Islamic religious values contained in the short story CARAKU MENCINTAI KANG ALFI (ALFIYAH LATIN) include "Hablum minallah and Hablum minan-nas". In relation to God, seven religious values are found, namely: (1) the value of faith (2) the value of endeavor, (3) the value of tawakkal, (4) the value of patience, (5) the value of guidance, (6) the value of monotheism, (7) God's help, while in relation to fellow human beings three religious values are found, namely: (1) mutual help among human beings, (2) mutual respect and respect for fellow human beings, (3) tolerance between religious communities. From some of the religious values presented by the author in this short story, he voiced the concept of Islamic Aqeedah which can be used as a good role model for readers. Because the contents of this short story include many religious teachings sourced from the Qur'an and Al-Hadith. And from here also the author emphasizes the importance of human relationships with God and human relationships with fellow human beings.
\end{abstract}

Keywords: values, religious, and short stories. 


\section{A. Pendahuluan}

Pada dasarnya kehidupan manusia sangatlah kompleks dengan berbagai masalah kehidupan. Kehidupan yang kompleks tersebut terdapat beberapa permasalahan mencakup hubungan manusia dengan Tuhannya (hubungan vertikal) danhubungan manusia dengan manusia(hubungan horizontal). Bagi seorang pengarang yang pek a terhadap permasalahan- permasalahan, dengan hasil perenungan, penghayatan, dan hasil imajinasinya, kemudian menuangkan gagasan/idenya tersebut dalam karya sastra yang kemudian melahirkan beragam karya sastra yang mencerminkan kehidupan nyata. Bahasa sebagai media sastra menggunakan tanda untuk mengekspresikan cerita (Junadi, 2021:72). Cerpen adalah salah satu bentukkarya sastra. Cerpen merupakan cerita fiksi dalam bentuk tulisan atau kata- kata dan mempunyai unsur pembangun di dalamnya. Sebuah cerpen biasanya menceritakan tentang kehidupan manusia dalamberinteraksi dengan tuhan, lingkungandan sesamanya. Dalam cerpen, si pengarang berusaha semaksimal mungkin untuk mengarahkan pembaca kepada gambaran-gambaran realita kehidupan melalui cerita yang terkandung dalam cerpen tersebut.

Menurut Mangunwijaya (dalam Lathief, 2008:175) juga mengemukakan bahwa segala sastraadalah religius. Religius diambil daribahasa Latin relego, dimaksudkan dengan menimbang kembali atau prihatin tentang (sesuatu hal). Seorang yang religius dapat diartikan sebagai manusia yang berarti, yangberhati nurani serius, saleh, teliti, dan penuh dengan pertimbangan spiritual. Religiusitas lebih melihat aspek yang 'di dalam lubuk hati', moving in the deep hart, riak getaran hati nurani pribadi, sikap personal yang sedikit banyak merupakan misteri bagi orang lain. Dengan demikian sikap religiusini lebih mengajak pada pribadi seseorang dengan Khaliqnya, bertingkah laku sesuai dengan karsa Tuhan. (Lathief, 2008: 175) Sastra religius adalah sastra yangmengandung nilai-nilai ajaran agama, moralitas, dan unsur estetika. Karya sastra seperti itu menunjukkan bahwa pengarang merasa terpanggil untuk menghadirkan nilai-nilai keagamaan kedalam karya sastra. Karya sastra yang menghadirkan pesanpesan keagamaan yang isi ceritanya diambil dari kitab-kitab suci keagamaan jumlahnya sangat banyak.

Keberadaan karya sastra jenis cerpen yang bertema keagamaan semakin merebak. Hal itu, bisa dilihat dari bermunculannya para pengarang yang cerpennya bernafaskan keagamaan, dalam hal ini bernafaskan Islam. Salah satu cerpen bernafaskan Islam yang 
mencerminkan nilai-nilai religius adalah cerpen CARAKU MENCINTAI KANG ALFI (ALFIYAH LATIN) Karya Lia Himmatul Ulya. Cerpen CARAKU MENCINTAI KANG ALFI (ALFIYAH LATIN) tersebut termasuk cerpen Islami.

Dalam cerpen CARAKU MENCINTAI KANG ALFI (ALFIYAH LATIN) terdapat nilai-nilai religius karena terdapat kaitan antara teks Al- Quran dan Al-Hadits. Untuk itu, perlu diteliti. Berdasarkan alasan-alasan itu penulis menganggap penting dan tertarik untuk meneliti cerpen CARAKU MENCINTAI KANG ALFI (ALFIYAH LATIN) Karya Lia Himmatul Ulya dari perspektif tekstualnya, dengan judul "Nilai-nilai Religius Islam dalam Cerpen CARAKU MENCINTAI KANG ALFI (ALFIYAH LATIN) Karya Lia Himmatul Ulya".

\section{B. Metode Penelitian}

Metode yang digunakan dalam penelitian ini adalah metode kualitatif dengan jenis penelitian yang berupa deskriptif, yaitu prosedur penelitian yang menghasilkan data berupa kata- kata tertulis atau lisan dari orang- orang dan perilaku yang dapat diamati, Bogdan dan Taylor (dalam Moleong, 2010:4). Penelitian deskriptif kualitatif suatu penelitian yang datanya secara kualitatif dan penjabarannya secara deskriptif (Rofiq, 2021:48).

Mengingat tujuan utama penelitian ini adalah menemukan hubungan antara cerpen CARAKU MENCINTAI KANG ALFI (ALFIYAH LATIN) Karya Lia Himmatul Ulyadengan Al-Qur'an dan Al- Hadits, maka pendekatan utama yang peneliti gunakan adalah pendekatan tekstual.

Teknik yang digunakan untuk mengumpulkan data dalam penelitian ini adalah teknik analisis teks (teknik tekstual) yang berupa paparan bahasa, teknik ini digunakan karena padadasarnya karya sastra merupakan paparan bahasa.

Cara pengumpulan data dengan teknik ini yaitu: (1) membaca cerpen dengan seksama, (2) menginterpretasikan makna paparan bahasa dengan cerpen yang berhubungan dengan penelitian, dan (3) merangkai data yang sesuai dengan nilai-nilai religius yang ada dalam teks cerpen CARAKU MENCINTAI KANG ALFI (ALFIYAH LATIN) dengan teks Al-Qur'an dan Al- Hadits.

Teknik analisis data yang digunakan dalam penelitian ini adalah teknik analisis, uraian, kupasan, dan teknik nonstatistik. Teknik ini berusaha menguraikan dan mendeskripsikan hasil pengolahandata yang ada. Data yang sudahdianalisis selanjutnya 
diubah menjadi data deskripsi, bukan berupa angka- angka.

Untuk menjaring data dalam penelitian ini adalah melakukan penelitian, yaitupeneliti sendiri sebagai instrumen utama. Peneliti dalam menjaring data menggunakan tabulasi data sebagai pelengkap guna menyimpulkan data yang telah dijaring dan selanjutnya dilakukan pengodean. Tabulasi data yang digunakan peneliti adalah tabulasi yang berisi nilai-nilai religi yang bersumber dari Al-Qur'an dan AlHadits, yakni; (1) dalam hubungannya dengan Allah, dan (2) dalam hubungannya dengan manusia.

\section{Hasil dan Pembahasan}

Dalam penelitian ini dipaparkan data dan temuan-temuan peneliti yang berkaitan erat dengan ayat-ayat Al-Qur'an dan Al-Hadits yang digunakan sebagai landasan untuk menemukan nilai-nilai religius yang terdapat dalam cerpen CARAKU MENCINTAI KANG ALFI (ALFIYAH LATIN) Karya Lia Himmatul Ulya, baik yang berhubungan antara manusia dengan Allah maupun hubungan manusia dengan manusia itu sendiri.

Untuk mengetahui adanya nilai- nilai religius dalam karya sastra memang bukan perkara yang mudah. Oleh karena itu, diperlukan kemampuan mengetahui konsep religious. Menurut Mustopo (2000:31) pokok religi itu adalah penyerahan diri pada Tuhan, dalam keyakinan bahwa manusia bergantungpadaTuhan, bahwa manusia tidak mampu memperoleh kekuatan dan keselamatannya sendiri. Karena itulah manusia menyerahkan dirinya pada Tuhan.

Cerita yang mengalir dari cerpen ini memang berasal dari inspirasi kisah- kisah nyata yang banyak diceritakan oleh penulis dan narasumber terpercaya. Dimensi konsidental dalam cerpen inipun oleh peneliti di buat untuk mengingatkan kita, sesungguhnya sebagai manusia kita mengalami banyak kejadian yang awalnya tidak menyenangkan, namun ternyata Allah menyembunyikan sisi menyenangkan pada kemudian hari.Pada akhirnya kita berucap, "benarlahTuhan Maha Pemberi Keajaiban.” Karena nilai-nilai religius yang ada diadopsi dari transformasi nilai-nilai yang ada dalam Al-qur'an dan Al- Hadits.

Dalam pembahasan ini, disajikan pembahasan dari hasil penelitian, di antaranya membahas wujud nilai-nilai religius yang berkaitan dengan hubungan antara manusia dengan Allah (vertical) dan hubungan manusia dengan manusia itu sendiri(horizontal). 


\section{Wujud Nilai-nilai Religius antara Manusia dengan Allah (Vertikal)}

Nilai religius ini memfokuskan relasi manusia dengan Tuhan. Dalam hubungan dengan Tuhan, manusia mendapatkan pengalamanmengagumkan yang tak terhapuskan mengenai personalitas luhur yang digambarkan secara metaforis dalam dogma-dogma agama, ritus-ritus, dan mitos. Untuk memahami nilai religius ini, hanya dengan iman dan cinta terhadap manusia dan dunialah manusia menyadari bahwa Tuhan itu merupakan Maha Pencipta, Yang Maha Tahu, dan Hakim bagi dunia ini. Melalui nilai religius ini, manusia berhubungan dengan Tuhannya melalui keimanan, kepatuhan, ikhtiar, tawakal, dan kerelaan berkorban bagi Tuhan.

Nilai-nilai religius yang adadalam cerpen ini oleh peneliti yang pembahasannya dengan uraiansebagai berikut.

\section{Nilai Keimanan}

Keimanan kata dasarnya adalah iman berasal dari bahasa Arab "Amana'Yu'minuImanan" artinya aman, damai, dan selamat sejahtera.

Menurut Taifiqurrokhman dalam Akidah Akhlak Kelas X MA. Semester Ganjil (2005:65) kata "iman" serumpun dengan kata "Amaan" artinya aman , damai, dan selamat sejahtera. Kata aman identik dengan kata amanah artinya orang mukmin harus dapat dipercaya ucapannya, perbuatannya, dan bertanggung jawab apabila diberi amanah, sehingga tercipta kehidupan yang damai, selamat, dan sejahtera. Secara istilah "iman" adalah mempercayai dalam hati, mengucapkan dengan lisan, dan mengamalkan dalam bentukperbuatan." (H.R. Ibnu Majah).

Menurut Supardjo iman menurut bahasa berarti percaya. Sedangkan, iman menurut istilah adalah percaya dalam hati, di ikrarkan dengan lisan, dan diamalkan atau dilakukan dengan perbuatan.

Para ulama salaf menjadikan amal termasuk unsur keimanan. Oleh sebab itu, iman bisa bertambah danberkurang, sebagaimana amal juga bertambah dan berkurang. Ini adalah definisi menurut Imam Malik, Imam Syafi'i, Imam Ahmad, Al Auza'i, Ishaq bin Rahawaih, madzhab Zhahiriyah dan segenap ulamalainnya.Dengan demikian definisi iman memiliki 5 karakter: keyakinan hati, perkataan lisan, dan amalperbuatan, bisa bertambah dan bisa berkurang.

Imam Syafi'i berkata, iman itu meliputi perkataan dan perbuatan. Dia bisa 
bertambah dan bisa berkurang.Bertambah dengan sebab ketaatan danberkurang dengan sebab kemaksiatan. Imam Ahmad juga mengatakan: iman bisa bertambah dan bisa berkurang. Iman bertambah dengan melakukan amal, dan berkurang dengan sebab meninggalkan amal. Sedangkan, Imam Bukhari mengatakan: Aku telah bertemu dengan lebih dari seribu orang ulama dari berbagai penjuru negeri, aku tidak pernah melihat mereka berselisih bahwasanya iman adalah perkataan dan perbuatan, bisa bertambah dan berkurang.

Perkataan iman yang berartimembenarkan itu disebutkan dalam al-Quran, di antaranya dalam SurahAt-Taubah ayat 62 yang berbunyi:

"Dia (Muhammad) itu membenarkan (mempercayai) kepada Allah dan membenarkan kepada para orang yang beriman." Iman itu ditujukan kepada Allah, kitab kitab dan Rasul. (Qs. At-taubah:62).

Keimanan adalah hal yang paling mendasar yang harus dimiliki seseorang. Allah memerintahkan agar ummat manusia beriman kepada-Nya, sebagaimana firman Allah dalam surat An-Nisa' ayat 136 yang artinya:

"Wahai orang-orang yang beriman. Tetaplah beriman kepada Allah dan RasulNya (Muhammad) dan kepada Kitab (Al Qur'an) yang diturunkan kepada RasulNya, serta kitab yang diturunkan sebelumnya.

Barang siapa ingkar kepada Allah, malaikat-malaikat-Nya, Kitab- kitab-Nya, Rasul-rasulNya, dan hari kemudian, maka sungguh orang itu telah tersesat sangat jauh.”(Qs.An- nisa:ayat 136)

Adapun nilai keimanan yang terdapat dalam cerita cerpen CARAKU MENCINTAI KANG ALFI (ALFIYAH LATIN) mencakup berikut ini.

\section{Bersyukur Kepada Allah}

Mayoritas masyarakat mengatakan:"sukurlah... atau untunglah ...”, terutama ketika kebaikan diperoleh atau terhindar dari suatu musibah yang lebih besar, baik terhadap dirinya sendiri maupun orang lain. Perkataan seperti ini merupakan ungkapan reflektif yang menunjukkanrasa lega, puas, senang, dan rasa terima kasih kepada Yang Maha Kuasa.

\section{Menerima Takdir Allah}

Konsep takdir, selalu menjadi perdebatan dan pertanyaan banyak orang. 
Belakangan ini, bagi umat Islam, Takdir merupakan bagian daripada Aqidah, karena merupakan bagian dariIman terhadap Qadla dan Qadar, kata Takdir ini merupakan kata yang berasal dari Qadar. Oleh karena itu, pemahaman tentang takdir ini sangat penting bagi seorang muslim. Sebab, pemahaman akan takdir ini akan menentukan arah dan sikap seorang muslim terhadap berbagai hal yang terjadi selama hidupnya.

\section{Nilai Ikhtiar}

Ikhtiar adalah usaha manusia untuk memenuhi kebutuhan dalam hidupnya, baik material, spiritual, kesehatan, maupun masa depannya agar tujuan hidupnya selamat sejahtera dunia dan akhirat terpenuhi. Ikhtiar juga dilakukan dengan sungguh-sungguh, sepenuh hati, dan semaksimal mungkin sesuai dengan kemampuan dan keterampilannya. Akan tetapi, usaha kita gagal, hendaknya kita tidak berputus asa.

Menurut Ibnu Rajab Ikhtiar adalah usaha manusia untuk memenuhi kebutuhan dalam hidupnya, baik material, spiritual, kesehatan, dan masa depannya agar tujuan hidupnya selamat sejahtera dunia dan akhirat terpenuhi. Ikhtiar juga dilakukan dengan sungguh- sungguh, sepenuh hati, dan semaksimal mungkin sesuai dengan kemampuan dan keterampilannya. Akan tetapi, usaha kita gagal, hendaknya kita tidak berputus.

Dalam menjalankan kehidupan, Allah memerintahkan kita untuk terus berusaha memberikan yang terbaik. Manusia terbaik adalah yang terus bergerak, memanfaatkan setiap potensi yang dia miliki untuk kehidupannya. Keseimbangan hidup di dunia dan akhirat haruslah diupayakan, sebagaimana yang seringkita dengar: "Berbuatlah untuk duniamu seolah kamu hidup selamanya, dan berbuatlah untuk akhiratmu, seolah kamu mati esok hari”.

\section{Nilai Tawakal}

Tawakal adalah sikap bersandar dan mempercayakan diri kepada Allah SWT, setelah berusaha dan berdoa. Tawakal adalah menyerahkan, menggantungkan diri, dan mengharapkan (segala sesuatu) kepada Allah setelah melakukan daya dan upaya, baik untuk menghindar dari sesuatu maupun untuk mendapatkan sesuatu. Dan pengertian tersebut, kita dapat mengambil salah satu kata kunci, yaitu menyerahkan atau dengan kata lain pasrah. Pasrah adalah bagian dari kewajiban manusia agar selalu menerima apa yang menjadi keputusan-Nya.

Menurut Robingan (20011:29)tawakal ialah sikap berserah diri kepada Allah Swt. Setelah berikhtiar dengan bersungguh-sungguh sesuai dengan 
kemampuan yang dimiliki. Bentuk perwujudannya adalah sikap menerima dengan ikhlas terhadap segala sesuatuyang diberikan oleh Allah swt. Atas ikhtiar atau usaha yang telah dilakukan.

Tawakal berasal dari kata ta'rif. Ta'rif sebagai sifat berserah diri sepenuhnya kepada ketetapan dan takdir Allah swt setelah melakukan ikhtiar dan usaha yang maksimal.

Berdo'a (Bermunajat) Doa adalah penyerahan, bukan tuntutan. Kita telah berusaha tetapi gagal. Kita telah meminta pertolongan makhluk, tetapi itu juga gagal. Tidak ada pilihan lagi kecuali menyerahkan segala urusan kepada Allah.

\section{Nilai Kesabaran}

Sabar adalah kesiapan rohani dan jasmani secara utuh untuk melaksanakan perintah-perintah Allah, menjauhi larangan- larangan-Nya,

serta siap menghadapi kesulitan- kesulitan yang dijumpai dalam hidupnya.

Supardjo (2011:43) mendefinisikan sabar adalah sikap teguh dalam menghadapi segala macam cobaan serta tidak melupakan ikhtiar yang dilakukan. Apabila ikhtiar yang dilakukan belum berhasil kita tidak mengeluh dan pantang putus asa.

Sikap sabar muncul dari keyakinan yang mendalam dan bertujuan untuk mencari keridhaan Allah. Untuk memperoleh derajat inilah orang harusselalu berdoa.sebagaimana yang tersebut dalam Q.S. 7 Al A'raaf ayat 126 sebagai berikut.

Dan engkau tidak melakukan balas dendam kepada kami, melainkan karena kami beriman kepada ayat-ayat Tuhan kami. (Mereka berdoa), "Ya Tuhan kami, limpahkanlah kesabaran kepada kami dan matikanlah kami dalam keadaan muslim."(Qs. Al-A’raaf: 126)

\section{Nilai Hidayah}

Hidayah secara bahasa berarti petunjuk. Lawan katanya adalah : ضـــالة (Dholalah) yang berarti "kesesatan". Secara istilah (terminologi), Hidayah ialah penjelasan dan petunjuk jalan yang akan menyampaikan kepada tujuan sehingga meraih kemenangan di sisi Allah.

Pengertian seperti ini dapat kita pahami melalui firman Allah surat Al- Baqarah ayat 5 , sebagai berikut :

"Mereka itulah yang tetap mendapat petunjuk dari Tuhan Pencipta mereka, dan 
(sebab itu) merekalah orang-orang yang sukses." (Qs. Al-Baqoroh: 5)

\section{Nilai Tauhid}

Tauhid secara etimologi berasal dari kata dasar "wahhada" (Arab) artinya mengesakan. Sedangkan tauhid secara terminologi menurut Ahmad Zuhdi Muhdlor (Kamus Kontemporer Arab - Indonesia) adalah meyakini keesaan Allah swt. baik dalam Dzat-Nya, perbuatan- perbuatan-Nya, maupun sifat-sifat- Nya.

Menurut Thohir tauhid adalah meng-Esakan Allah, suatu kepercayaan kepada Tuhan yang Maha Esa (faith in unity of God). Suatu kepercayaan yang menegaskan bahwa hanya Tuhanlah yang menciptakan, memberi hukum- hukum, mengatur dan mendidik alam semesta ini (Tauhid Rububiyyah).

Setiap manusia wajib hukumnya meyakini bahwa Allah adalah satusatunya Dzat yang harus disembah. Allah akan memberi hukuman dengan seberat-beratnya kepada orang- orang yang menyekutukan Allah, karena perbuatan itu adalah perbuatan aniaya yang amat berat. Allah tidak akan pernah mengampuni perbuatan syirik yang dilakukan oleh manusia, kecuali dosa-dosa selain syirik.Sebagaimana firman Allah dalam Q.S. 4 An Nisaa' ayat 48 sebagai berikut.

Sesungguhnya Allah tidak akan mengampuni dosa syirik, dan Dia mengampuni segala dosa selain dari (syirik) itu, bagi siapa yang dikehendakinya. Barang siapa yang mempersekutukan Allah, maka sungguh ia telah berbuat dosa yang besar.(Qs. An-Nisaa':48)

\section{Pertolongan Allah}

Dalam komunitas masyarakat yang ingkar kepada Allah SWT. merekamembangun sifat-sifat mereka menurut kekuatan atau status yang mereka punya agar seseorang memiliki rasa percaya diri, ia harus kaya, terkenal, cantik, atau tampan. Menjadi anak dari orang yang "dihormati" juga itu menjadi alasan penting agar mendapat rasa percaya diri pada masyarakat.

Pertolongan yang Allah berikan kepada hambanya yang sedang berada dalam kesulitan. Dengan cara yang mungkin tidak masuk akal, tapi itulah Allah. Allah Maha Besar atas segala sesuatu. PertolonganAllah sangat penting artinya bagi kehidupan manusia. Oleh karena itu, kita harus berusaha supaya memperoleh pertolongan Allah.

Salah satu tanda bahwa seseorang telah memperoleh pertolongan Allah adalah apabila dia telah memenuhi panggilan Allah, yaitu memeluk agama Islam secara 
keseluruhan. Sebagaimana perintah Allah dalam Q.S. Al- Baqarah ayat 208 sebagai berikut:

Hai orang-orang yang beriman, masuklah kamu ke dalam Islam secara keseluruhannya, dan janganlah kamu turut langkah-langkah syaitan. Sesungguhnya syaitan itu musuh yang nyata bagimu.(Qs. Al-Baqoroh: 208)

\section{Nilai-Nilai Religius dalam Hubungannya Sesama Manusia}

Nilai-nilai Religius dalam hubungannya sesama Manusia. Peneliti menemukan tiga nilai-nilai religius dalam cerpen ini, yaitu:

\section{Saling Tolong Menolong antar Sesama Umat Manusia}

Tolong menolong antar sesama umat adalah salah satu ajaran agama Islam yang hams dilaksanakan oleh seluruh umat Islam, selama tolong menolong itu menjadi jembatan bagi kita untuk melakukan kebaikan dan takwa kepada Allah SWT.

Menurut Nurdi (2009:17) Tolong-menolong adalah termasuk persoalan-persoalan yang penting dilaksanakan oleh seluruh umat manusia secara bergantian. Sebab tidak mungkin seorang manusia itu akan dapat hidup sendiri-sendiri tanpa menggunakan cara pertukaran kepentingan dan kemanfaatan.

Saling Tolong Menolong antar Sesama Umat Manusia adalah sifat yang terpuji, sedangkan tolong menolong dalam kejelekan dan permusuhan adalah sifat yang tercela, Namun dikarenakan kemampuan manusia dalam memberikan bantuan pun tidaklah sama dan demikian pula kebutuhan setiap orang juga berbeda- beda, maka hendaknya kita membantu sesuai dengan kemampuan kita dan kita perlu pula memperhatikan kebutuhan orang yang akan kita bantu.

Di zaman yang sudah mulai tua ini, di mana orang-orang mulai cenderung hidup sendiri-sendiri, sehingga tidak lagi ada orang yang peduli terhadap kaum yang lemah, orang yang kaya tidak lagi mau membantu orang yang miskin, orang yang kuat tidak lagi mau menolong kaum dhu'afa', dan keangkaramurkaan semakin merajalela. Padahal dengan tegas Allah memerintahkan kepada kita agar selalu tolong menolong sesama umat Islam. Sebagaimana potongan ayat 2 dalam Q.S. Al Maaidah sebagai berikut.

"Dan tolong menolonglah kamu dalam (mengerjakan) kebaikan dan takwa."(Qs. Al-Maidah:2) 


\section{Saling Menghormati dan Menghargai Sesama Manusia}

Menurut Mahmud, Ihtiram artinya saling menghargai atau saling hormat menghormati kepada sesama manusia. Saling harga menghargai adalah satu sikap yang harus dimiliki oleh setiap muslim sebagai wujud dari Akhlaqul mahmudah.

Islam sangat menekankan pada dua dimensi nilai yang harus selalu diwujudkan yaitu akhlaq yang terpuji dan 'aqidah atau keimanan yang benar, dua-duanya harus seiring sejalan.Aqidah yang benar akan membuahkan akhlaq yang baik. Akhlaq yang baik harus berakar pada aqidah yang benar.

\section{Toleransi antar Umat Beragama}

Dalam Kamus Umum Bahasa Indonesia, toleransi berasal dari kata "toleran" (Inggris: tolerance; Arab: tasamuh) yang berarti batas ukur untuk penambahan atau pengurangan yang masih diperbolehkan. Secara etimologi, toleransi adalah kesabaran, ketahanan emosional, dan kelapangan dada. Sedangkan menurut istilah (terminology), toleransi yaitu bersifat atau bersikap menenggang (menghargai, membiarkan, membolehkan) pendirian (pendapat, pandangan, kepercayaan, kebiasaan) yang berbeda dan atau yang bertentangan dengan pendiriannya.

Toleransi artinya tidak mencampuri urusan pribadi pihak lain yang telah diberiakan oleh Allah sebagai kebebasan manusia dan tidak merasa terganggu oleh aktivitas orang lain yang berbeda tersebut. Masalah yang menonjol dari sikap toleran ini adalah sikap keagamaan, di mana setiap manusia memiliki kebebasan dalam beragama dan tidak ada hak bagi orang lain yang berbeda agama untuk mencampurinya. Keyakinan beragama tidak dapat dipaksakan. Akal dan pengalaman hidup keagamaan manusia mampu menentukan sendiri agama yang dianggap benar. (Thohir dkk, 2012:158)

\section{Kesimpulan}

Berdasarkan hasil analisa dan pembahasan yang telah dilakukan, maka dapat disimpulkan bahwa nilai- nilai religius Islam dalam cerpen CARAKU MENCINTAI KANG ALFI (ALFIYAH LATIN) Karya Hevy Tiana Rosa sebagai berikut:

Nilai-nilai Religius yang Berhubungan antara manusia dengan Allah. Dalam cerpen ini terdapat tujuh nilai-nilai religius yaitu: (1) nilai keimanan, (2)nilai ikhtiar, (3) nilai tawakal,(4) nilai kesabaran, (5) nilai hidayah, (6) nilai tauhid, dan (7) pertolongan Allah. Adapun nilai-nilai religius dalam hubungannya sesamamanusia. 
Hasil penelitian ini menemukan tiga nilai- nilai religius dalam cerpen ini, yaitu: (1) saling tolong menolong antarsesama umat manusia,(2) saling menghormati dan menghargai sesama manusia, dan (3) toleransi antarumat beragama.

\section{Daftar Rujukan}

Asngadi Rofiq, K. A. N. (2021). Proses Morfologis Reduplikasi dalam Buku Generasi Optimis Karya Ahmad Rifa'i Rif'an. PENEROKA, 1(01), 42-59.

Syafi' Junadi, R. K. L. (2021). Fenomena Bahasa Gaul sebagai Kreativitas Linguistik dalam Media Sosial Instagram pada Era Milenial. PENEROKA, 1(01), 68-89.

Bakri, Ahmad Abdurraziq. 2015. Ringkasan Ihya' 'ulumuddin. Sahara Intisains.

Jabrohim. 2014. Teori penelitian sastra. Yogyakarta: Pustaka Pelajar Katsir, Ismail. 774 H. Tafsir Ibnu Katsir. Semarang: Thoha Putra.

Lathief, Supaat I. 2008. Sastra: Eksistensialisme-Mistisisme Religius. Lamongan: Pustaka Ilalang Moleong. J. 2000. Metodologi Penelitian Kualitatif. Bandung: Remaja Rosda.

Nurgiyantoro, Burhan. 2010. Teori pengkajian fiksi. Yogyakarta: gajah madauniversity press.

Pradopo, R. D. 2012. Beberapa Teori Sastra, Metode Kritik, Dan Penerapannya. Yogyakarta: Pustaka Pelajar.

Robingan. 2011. Teladan Utama Pendidikan Agama Islam. Solo: Tiga Serangkai.

Ratna, Nyoman Kutha. 2013. Teori, Metode, dan Teknik Penelitian Sastra. Yogyakarta: Pustaka Pelajar.

Rosa, Helvy Tiana. 2011. CARAKU MENCINTAI KANG ALFI (ALFIYAH LATIN). Depok:Asma Nadia.

Supardjo.2011. Mutiara Pendidikan Agama Islam 1. Solo: Wangsa Jatra Lestari

Thohir, dkk. 2012. Pendidikan Agama Islam. Malang: Pusat Pembinaan Agama Universitas Brawijaya. 